\title{
MEU PERSONAGEM INESQUECÍVEL
}

\section{Indignação é o ponto alto da obra do autor: percorre os meandros que separam ficção e realidade e mostra-se sintonizado com os dramas sociopolíticos de seu tempo}

Apesar das muitas e cada vez mais avançadas conquistas da moderna tecnologia, ainda há pessoas que, em matéria de limpeza, preferem varrer o lixo para debaixo do tapete ao invés de usarem o aspirador de pó, por exemplo. Isso pode se dar por pura preguiça. Ou por falta de condições econômicas para comprar o eletrodoméstico ou ainda poderá tratar-se da simples configuração de um fator cultural. Qualquer que seja o motivo, entretanto, o lado desagradável de tão comezinha questão é sabermos que o lixo assim negligentemente escondido, reaparece, juntando-se a novas camadas de sujeira. Se a operação se repetir por algum tempo, não será difícil imaginar as conseqüências daí advindas...

Penso que alguma coisa mais ou menos parecida tem se passado com o nosso Brasil. Muito do lixo político brasileiro, desde 1964, vem sendo varrido com negligência para debaixo do tapete da nossa indiferença e do nosso esquecimento. E hoje é o que se vê por aí: santa, arrogante e quase fanática hipocrisia neoliberal dos últimos dias... Meu último romance, Florão da América ${ }^{1}$, é antes de tudo uma parábola sobre esse lixo acumulado, e sobre essa hipocrisia. Uma fantasia ingênua, se quiserem, um sonho de quem insiste em não perder a esperança nos valores e nas virtudes do pensamento humanista e no socialismo histórico. Mas escrevê-lo significou para

\begin{tabular}{l} 
O AUTOR \\
\hline Izaías Almada \\
Jornalista e autor dos romances A metada arran- \\
cada de mim e O medo por trás das janelas; do \\
roteiro do filme Sinais de fogo e da peça Uma \\
questão de imagem, prêmio Vladimir Herzog de \\
Teatro 1995.
\end{tabular}
mim, ao mesmo tempo, um ato de amor e um vomitório.

Em 1991, tinha eu acabado de publicar $\mathbf{O}$ Medo por trás das Janelas, fui convidado para palestrar em algu-

1. Os interessados podem encontrar o romance Florão da América na Editora Estação Liberdade - Rua Fagundes, 43 - 01508-030 São Paulo - SP - Fones: (011) 2706830 e 278 3013. 
mas faculdades paulistas. Embora o tema desse romance esteja vincado em episódios da nossa história colonial, fui surpreendido - na maioria das vezes - com questões sobre o Brasil contemporâneo. Interesse natural e saudável. Estávamos vivendo o primeiro ano do governo Collor/Paulo César Farias... Chamou minha atenção, nos debates, o fato de que boa parte daqueles estudantes, jovens entre os $18 \mathrm{e}$ os 21 anos na sua maioria, não estivessem familiarizados com a recente história política do país. Houve mesmo quem ignorasse o período da ditadura militar entre nós ou o muito do que aí se passou. Posso assegurar que foi num desses encontros que nasceu a idéia de Florão da América.

Resolvi tomar para mim a tarefa de dar forma a uma história que chamasse a atenção para o nosso lixo acumulado, para o nosso entulho. Porque o Brasil contemporâneo outra coisa não tem sido senão a caixa desse grande e vibrante entulho de contradições econômicas, políticas e sociais de um novo fin de siècle, sempre ocultados sob tapetes de desenhos mais ou menos democráticos. Pouco estudado ou convenientemente ignorado, o fenômeno entre nós tem sido cada vez melhor aproveitado pelos donos do poder e seus apaniguados e também por seus porta-vozes nos meios de comunicação social.

\section{DEDO NA FERIDA}

Escrever um livro é uma tarefa como outra qualquer: implica dificuldades, riscos, inseguranças... e prazer. Mas nem sempre nos deixa satisfeitos, por melhor que nos tenhamos aplicado; ou também não satisfaz plenamente àqueles que o lêem, por melhor disposição que tenham os leitores para com a história ou para com o autor. Essa tarefa correrá maiores ou menores riscos consoante a relação que se possa estabelecer entre o tema escolhido pelo autor, o momento da sua publicação, e o nível de bem estar social do leitor, seu estágio de cidadania, mais até do que sua posição estética, política ou mesmo ideológica. No Brasil, isto se torna um pouquinho mais complicado, podendo significar a morte antecipada de uma obra ou seu eventual sucesso.

Basta pensarmos que quase metade da população é analfabeta e não lê, e a outra metade — que lê pouco — acostumou-se a pensar a realidade em que vive através de dois partidos políticos, uma rede de televisão, dois ou três jornais e uma revista semanal. Foi com preocupações desse tipo que mergulhei em Florão da América. 
A morte ficcional de Roberto Marinho, Delfin Netto, um torturador da ditadura, um publicitário de prestígio e um delegado de polícia da década de 90 fazem, quanto a mim, o desenho de um Brasil que muitos de nós desejaríamos ver ultrapassado, mas que insiste em continuar, agora com novos disfarces, e bem mais perversos do que poderíamos imaginar... É também a morte ficcional da informação, da economia, da política e da publicidade com que nos habituamos a conviver. E que pode mudar, se quisermos. Um serial killer de idéias. O livro parte de uma premissa: e se o Brasil pudesse ser diferente?

Quando o capitalismo já mostrou e provou que pode ir mudando de cara, mas sem com isso resolver os problemas fundamentais de sobrevivência condigna do ser humano, e que o socialismo se transformou para muitos de sonho em pesadelo ou frustação, é mais do que urgente encontrar novas maneiras de pensar a realidade à nossa volta.

Encontrar alternativas para o pensamento e para a ação política, sem perder de vista os objetivos de que - quanto a mim - não deveríamos jamais abrir mão: melhor distribuição da riqueza, justiça social e solidariedade entre povos e raças. Isso, para ficar nos mais imediatos...

Ficção, Florão da América quer pensar a realidade de outra maneira. Ou chamar a atenção para esse ponto de vista. E para isso, é preciso não temer os dogmas de qualquer natureza, particularmente os ideológicos que se fingem "modernizantes". Nem tudo que pertence ao passado é conservador, assim como nem tudo que é novo, só por ser novo, é revolucionário e progressista. Haverá inúmeros exemplos a respeito. Um opúsculo de Simone de Beauvoir, escrito há mais de trinta anos (O Pensamento de Direita Hoje), trata bem o assunto. É preciso pôr o dedo na ferida, no entanto, e não ter medo de dizer certas verdades, principalmente se elas incomodam os poderosos. Os que mandaram e mandam nesse país, desde que Cabral aportou na Bahia, invariavelmente foram ou são gente da pior espécie, e quanto a isso não há que ter meias medidas. Mais sofisticados com o passar dos anos, os donos do poder no Brasil agora já lançam mão de capatazes diplomados no exterior, como se o eventual conhecimento up to date de determinadas idéias e teorias - principalmente as econômicas - pudesse redimi-los junto à opinião pública internacional (porque a nacional são eles mesmos que a fazem) ou junto ao Pai Eterno, se assim preferirem os espíritos mais religiosos. Haja sociologia a respeito... 


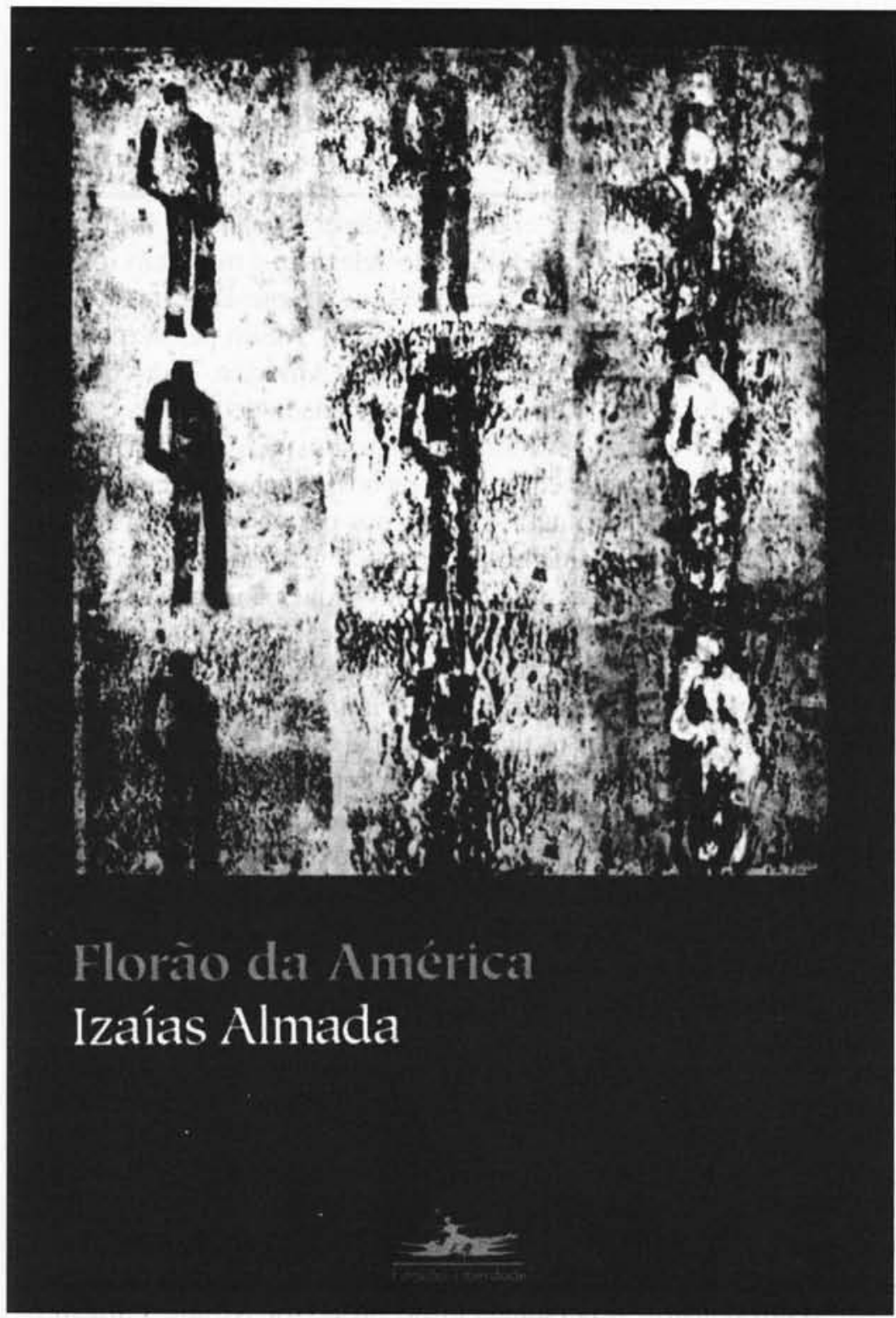

\section{SONHO}

Há é que recriar utopias, reinventar sonhos, buscar saídas que se equivalham em seriedade à mesma seriedade da fome e da ignorância, pois sem sonhar o homem não passa de um número de cartão de crédito ou de um talão de cheques e acaba tristemente, o brasileiro por exemplo, como um consumidor de quinquilharias vendidas em Miami ou no Paraguai. 
Escrever é exercer também essa sensibilidade: mesmo contra a maré, o escritor deve estar atento ao que se passa à sua volta $e$ ir buscar subsídios para construir alguma coisa que quebre a mesmice, que confronte a unanimidade, que ultrapasse o óbvio.

E hoje o óbvio, a mesmice e a unanimidade boçal, com licença de Nélson Rodrigues, são a Rede Globo de Televisão e os jornais diários, a nossa organização política e os partidos que a representam, a publicidade mentirosa do nosso consumismo caboclo. Assim pensa o professor Arthur, o personagem central de Florão da América. Todos, ou melhor, os formadores de opinião de uma sociedade debochada e falsa, querem nos fazer crer na economia de mercado, na livre manifestação do pensamento, no racismo edulcorado da nossa sociedade, como se vivêssemos no melhor dos mundos, apesar dos percalços aparentes e circunstanciais. Mentira! Canalhice, hipocrisia! Isso só é verdade para uma minoria de cidadãos, assim mesmo desde que não ponham em causa a estrutura de poder que mantém essa situação. Ao contrário, nunca se ofendeu tanto a inteligência humana como se fez nestes últimos anos no Brasil. A corrupção financeira já é hoje um dado adquirido. Uma sujeirinha que se varre todos os dias para debaixo do tapete. $O$ problema se transferiu para um outro patamar, o da corrupção das palavras, das idéias. Até no campo religioso inverteram-se os fundamentos. Há bem pouco tempo, o reino dos Céus haveria de pertencer aos oprimidos, aos desafortunados e explorados. Hoje, Deus abençoa aqueles que conseguem amealhar mais aqui na vida terrena e que possam contribuir com polpudos dízimos para a manutenção dos gigolôs da fé. A pior humilhação é aquela que é feita com arrogância e impunidade, é perceber o sorriso irônico do novo rico diante da miséria.

É preciso reverter o quadro, criar alternativas urgentes, repor valores que foram esquecidos ou adormecidos tais como a solidariedade, a lealdade, a competência profissional, o trabalho feito com saber e honestidade, o respeito pelas leis que visam ao bem público. E não ter vergonha de defender esses ideais.

Assim construí o personagem do professor Arthur, um estranho no ninho. Ao lado da sua obstinação, do seu desespero, um corre-corre de almas aflitas, de vaidades sem fogueira, de inúteis a serviço do bem pessoal. Digam o que disserem os nossos filósofos de plantão, os nossos ideólogos da boca do mato, mas nada continua ainda incomodando tanto certas pessoas entre nós do que saber que algumas questões não podem ser varridas para debaixo dos tapetes. Entre elas, o simples fato de que continuamos a ser um conjunto de cafuzos, mulatos e caboclos à procura de uma verdadeira identidade cultural da qual possamos nos orgulhar... 